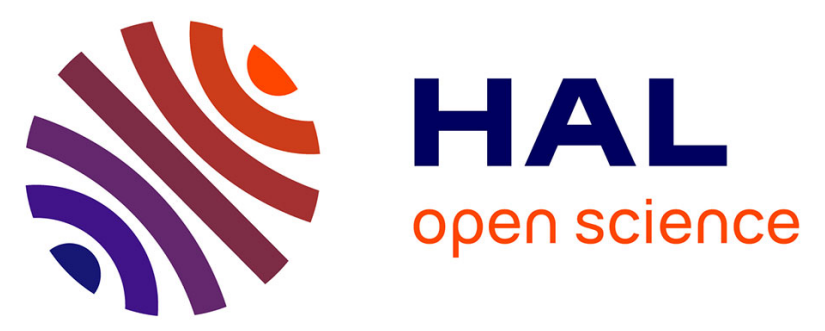

\title{
Selection and use of a multi-criteria decision aiding method in the context of conceptual design with imprecise information: Application to a solar collector development
}

\author{
Mehdi El Amine, Jérôme Pailhes, Nicolas Perry
}

\section{To cite this version:}

Mehdi El Amine, Jérôme Pailhes, Nicolas Perry. Selection and use of a multi-criteria decision aiding method in the context of conceptual design with imprecise information: Application to a solar collector development. Concurrent Engineering: Research and Applications, 2016, 24 (1), pp.35-47. 10.1177/1063293X15613838. hal-01301192

\author{
HAL Id: hal-01301192 \\ https://hal.science/hal-01301192
}

Submitted on 11 Apr 2016

HAL is a multi-disciplinary open access archive for the deposit and dissemination of scientific research documents, whether they are published or not. The documents may come from teaching and research institutions in France or abroad, or from public or private research centers.
L'archive ouverte pluridisciplinaire HAL, est destinée au dépôt et à la diffusion de documents scientifiques de niveau recherche, publiés ou non, émanant des établissements d'enseignement et de recherche français ou étrangers, des laboratoires publics ou privés. 


\title{
Selection and use of a multi-criteria decision aiding method in the context of conceptual design with imprecise information: Application to a solar collector development
}

\author{
Mehdi El Amine, Jérôme Pailhès and Nicolas Perry
}

\begin{abstract}
Making decisions on a sound basis in early phases is one of the most difficult challenges in the product development process, especially when dealing with immature concepts. Moreover, life-cycle cost can be influenced up to $70 \%$ by decisions taken during the conceptual design phases. The need for reliable multi-criteria decision aiding methods is thus greater in these phases. Various multi-criteria decision aiding methods are proposed and used in the literature. The main criticism of these methods is that they usually produce contradictory results for the same problem. In this work, seven widely used multi-criteria decision aiding methods (weighed sum, weighted product, Kim and Lin, compromise programming, TOPSIS, quadratic mean and ELECTRE I) are analysed. This analysis was based on a real industrial case to develop a solar collector. The proposed multi-criteria decision aiding methods were compared in terms of three criteria deemed relevant in the relevant context: $(\mathrm{I})$ adaptation of the type of results the multi-criteria decision aiding method is expected to bring, (2) correct handling of input information and (3) adaptation of the degree of compensation. Based on these criteria, it was proven that weighted product is the most appropriate multi-criteria decision aiding method in our case. In addition, it has been demonstrated that sensitivity analysis can improve the benefit of using the multi-criteria decision aiding method chosen when dealing with imprecise information due to immaturity of concepts.
\end{abstract}

\section{Keywords}

conceptual design phase, multi-criteria decision aiding methods, concept maturity, imprecision, sensitivity study

\section{Introduction}

Decision support was first proposed by Nobel Prize winner Herbert Simon in the 1960s (Simon, 1960). Broadly speaking, decision-making is conducted in four steps: (1) identifying the problem, (2) generating design concepts, (3) evaluating design concepts via evaluation schemes and (4) selecting the best concept. The research community in decision support methods usually recognizes that the most critical step in the decision-making process is how to choose among a given number of design concepts (step (4)). The ability of decisionmakers (DMs) to make the best choice is strongly conditioned by two factors: (1) having a clear definition of design objectives and requirements and (2) being able to evaluate or predict the performance of the proposed concepts against these objectives and requirements. However, imprecisions and vagueness are inherent in engineering design and they affect both design objectives and concepts evaluation schemes. This is particularly true in the conceptual design phases. Paradoxically, life-cycle cost can be influenced up to $70 \%$ by decisions taken during these phases (Zimmer and Zablit, 2001). It is thus very important to adopt appropriate theories and methodologies to structure and ease the decision-making process. This can significantly reduce product development lead-time as well as the amount of human and material resources involved in the development process.

Arts et Métiers ParisTech, I2M - UMR 5295, Talence, France

Corresponding author:

Mehdi El Amine, Arts et Métiers ParisTech, I2M - UMR 5295, F-33400

Talence, France.

Email: mehdi.el-amine@ensam.eu 
Multi-criteria decision-making process can be decomposed into three principal steps (Guitouni and Martel, 1998): (1) observation, when data are collected about each concept (mass, maximum stress, carbon footprint, etc.), (2) interpretation, when DMs express their preferences for each design criterion on the basis of the data collected in the observation step and (3) aggregation, when DMs combine the interpretation step outcomes for the different design criteria in order to determine the best concept(s). This process represents the natural way of human thinking when confronted with a multi-criteria decision problem. However, when the DM is facing a complex decisionmaking problem (with many concepts and many criteria), it becomes difficult for him to intuitively follow this process, especially to combine information in an appropriate way. Multi-criteria decision aiding (MCDA) methods can be used to aid in multi-criteria decision-making.

Various MCDA methods are proposed and adopted by researchers and engineers to support decisionmaking in engineering design. Choosing the 'right' MCDA method to compare multiple concepts is a crucial issue since these methods may yield contradictory results for the same problem (Guitouni and Martel, 1998; Mahmoud and Garcia, 2000; Triantaphyllou and Lin, 1996; Zanakis et al., 1998). There are two families of MCDA methods: (1) multi-criteria selection methods, where interpretation step outcomes are taken into account simultaneously to compare initial concepts, and (2) the family of multi-attribute utility theory (MAUT) methods, that consists of aggregating the different interpretation step outcomes into a single attribute of evaluation, which has to be maximized. In this study, this numerical attribute is called the overall preference value (OPV). It reflects the overall utility of the design concept. The multi-criteria decision problem is thus transformed into a mono-criteria decision problem. In the case of MAUT methods, the interpretation step is formalized by associating a numerical attribute to each objective to express its level of satisfaction. In this article, this attribute is called local preference value (LPV) and is comprised between 0 and 1. The closer a LPV is to 1 , the more satisfied is the corresponding objective.

The main objective of this article is to identify the relevant criteria to consider when selecting a MCDA method in the context of decision-making in conceptual design phase. The second objective is to investigate the benefit of using a sensitivity study with a MCDA method to deal with imprecise information due to the immaturity of initial concepts. In order to illustrate the proposed approach, many MCDA methods are evaluated and compared in a real industrial case.

\section{State of the art}

Stewart (1992) produced a theoretical review by identifying pitfalls in using various MCDA methods. He concluded that in selecting an appropriate method to use, the following desiderata must be identified: (1) the input information required from the DM should be operationally meaningful and free from ambiguities of meaning, (2) the translation of this input information into partial or complete recommendations should be consistent with the input information used and with reasonable behavioural assumptions, and should be as far as possible transparent to the DM, and (3) the method should be simple and efficient to use. Ozernoy (1988) proposed a MCDA expert system to guide the DM in selecting an appropriate method. This system uses a database containing the different MCDA methods with their characteristics. To select an appropriate method, the system matches the characteristics of the decisionmaking situation with those of the MCDA method. These characteristics fall into three categories: characteristics of the decision problem, characteristics of the DM and resource constraints. A similar system was used by Sun et al. (2012) for an aircraft conceptual design process. Based on the analysis of different MCDA methods and the review of the psycho-cognitive literature, Guitouni et al. (1998) proposed six guidelines to help DM choose a MCDA method. The proposed guidelines are as follows: adaptation of the type of results produced by MCDA method, correct handling of input information, appropriateness of the degree of compensation of the method, respect for the fundamental hypothesis of the method, adaptation of the decision support system that accompanies the method and adaptation of the preference elucidation mode with DM cognition.

These studies propose some relevant criteria to consider when selecting a MCDA method. However, they do not give the order in which these criteria should be considered or even their relative importance. The following question thus arises: what is the DM supposed to do when no method exactly satisfies all the suggested criteria? In this situation, it becomes necessary to adopt a compromise by accepting the degradation or even the non-compliance of some criteria. However, this requires the establishment of a certain hierarchy, from the most important criterion to the least important. Recently, Roy and Slowinski (2013) established a set of questions to guide DM in selecting a MCDA method. In addition, they present these questions in a hierarchical order (from the most pertinent question to the least pertinent). They argue that the most crucial question is what type of results the method is expected to bring. The other pertinent questions concern requirements on preference scales, acquisition of preference information, 
handling of imperfect knowledge, acceptance of compensation among criteria and existence of interaction among criteria. The least pertinent questions are about the ease of understanding by stakeholders and the presence or not of axiomatic characterization of the method. This hierarchical order in the establishment of questions facilitates the selection of a MCDA method. However, the authors argue that the proposed hierarchy is quite general and may appear incomplete or inadequate in some specific cases. According to Roy and Slowinski (2013), the content of the proposed questions, and the diversity of answers that can be given with respect to the decision context, lead to great difficulties to conceive a family of criteria which would permit a multi-criteria formulation of the problem of choosing a MCDA method. Many other authors claim that the choice of an appropriate method is one of the most difficult problems to which the DM is faced in MCDA (Belton and Stewart, 2002; Guitouni and Martel, 1998; Roy and Slowinski, 2013). Added to this, many authors argue that the choice of the most appropriate MCDA method depends very much on the decision-making context under consideration (Guitouni and Martel, 1998; Hobbs et al., 1992; Roy and Slowinski, 2013;
Stewart, 1992). Based on these elements, it becomes clear that in order to effectively address the issue of MCDA method selection, one should first determine a specific context of decision-making in which the MCDA methods are evaluated. For example, Masseia et al. (2014) investigate selecting a MCDA method for the specific case of environmental management decisions. To our knowledge, there have been no attempts to date to investigate the selection of MCDA methods in the specific case of conceptual design decisions.

MAUT is a family of MCDA methods in which an aggregation operator is used to obtain a single evaluation attribute (more explanations in section 'Introduction'). As this family of MCDA methods is considered in this study, mathematical axioms that must be respected by an aggregation operator are investigated. Keeney and Raiffa (1994) established a set of mathematical axioms applicable for the general case of decision-making (without referring to a specific context). Scott (1999) constructed the set of mathematical axioms to respect in the case of engineering design. They are shown in Table $1 . \mathrm{w}_{\mathrm{i}}$ refers to weight of a criterion i. The axioms of monotonicity, commutativity and continuity are common to many multi-attribute

Table I. Mathematical axioms for a design-appropriate aggregation operator (Scott, 1999).

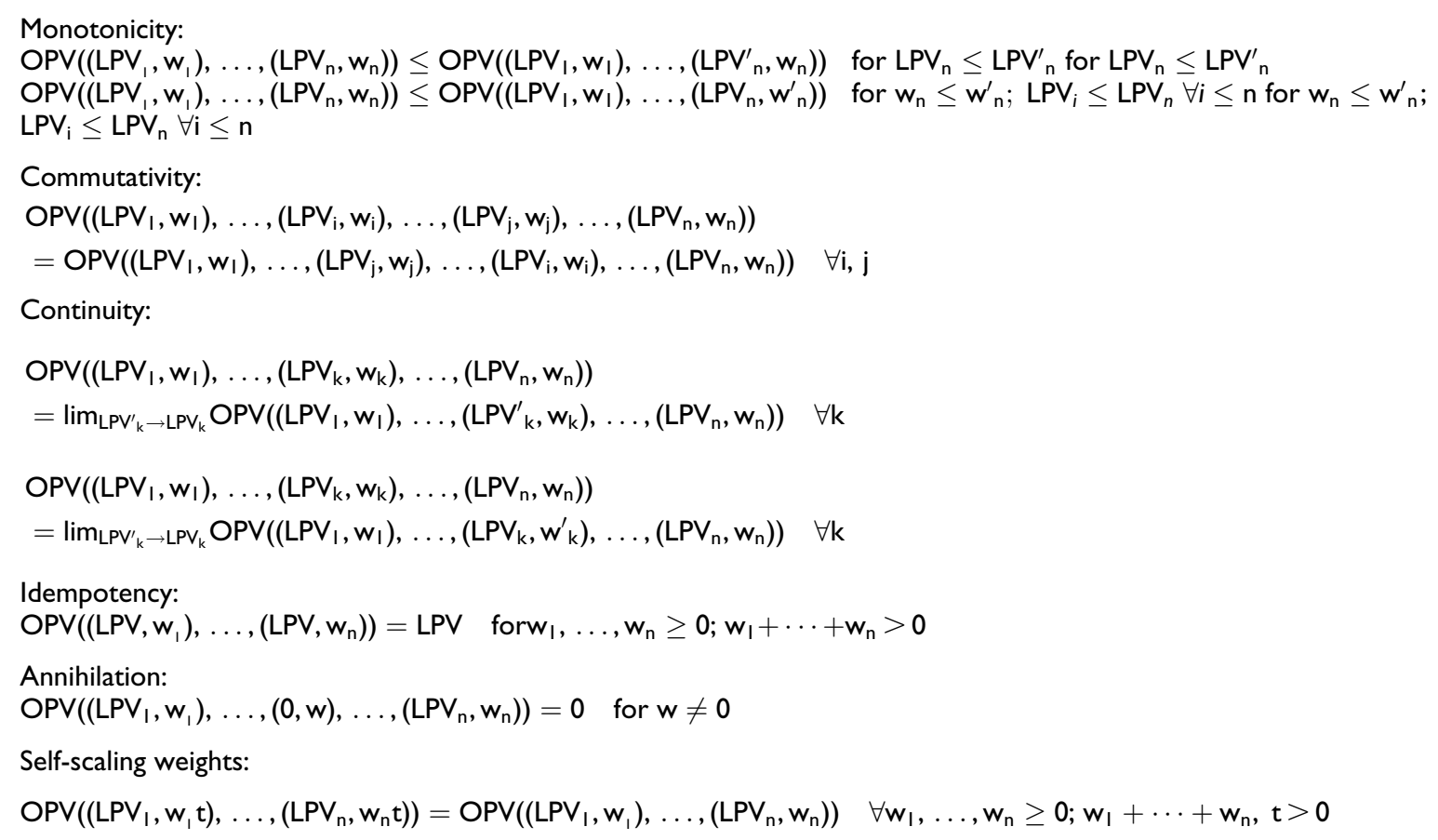

Zero weights:

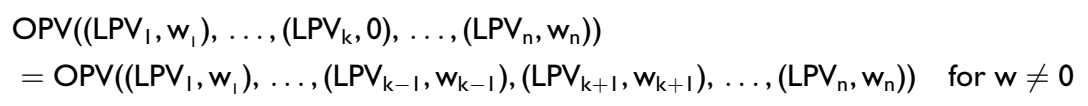

$\mathrm{OPV}_{\mathrm{i}}$ : overall preference value for criterion $\mathrm{i}$ LPV: local preference value; $\mathrm{w}_{\mathrm{i}}$ : weight of criterion $\mathrm{i}$. 
decision-making schemes, and they are uncontroversial (Fodor and Roubens, 1994; Keeney and Raiffa, 1994). The axiom of annihilation is specific to engineering design and it is recognized by other authors (Biegel and Pecht, 1991; Otto and Antonsson, 1993; Vincent, 1983). It states that if the satisfaction for any criterion of the proposed design is null (acceptance thresholds not reached), then the design solution is not valid, regardless of the degree of satisfaction for the other criteria. The aggregation operators respecting these axioms are called design-appropriate aggregation operators. The aggregation operators respecting the axiom of annihilation are called conservative aggregation operators.

These axioms restrict the field of suitable aggregation operators since they must be verified in the case of engineering design. However, they are not a guarantee of finding the 'most suitable' aggregation operator. In addition to these axioms, Grabisch (1996) suggests some desired behavioural properties for an aggregation operator: possibility of expressing weights of importance on criteria if necessary, possibility of expressing the behaviour of the DM, possibility of expressing a compensatory effect or an interaction between criteria, and possibility of an easy semantical interpretation of aggregation operator parameters.

\section{Presentation of MCDA methods}

In this study, seven aggregation operators were considered (weighed sum, quadratic mean, weighted product (WP), Kim and Lin (KL), two variants of compromise programming (CP) and TOPSIS (Technique for Order Preference by Similarity to Ideal Solution) as well as an outranking method (ELECTRE I - ELimination Et Choix Traduisant la REalité I). The weighted sum (WS) is the most widely used aggregation operator. The weights assignment $\left(\mathrm{w}_{\mathrm{i}}\right)$ reflects the proportional importance of the different aggregated variables $\left(\mathrm{LPV}_{\mathrm{i}}\right)$. The OPV is expressed by equation (1). The quadratic mean is also used in this study and its OPV is expressed by equation (2)

$$
\begin{gathered}
\mathrm{OPV}=\sum_{\mathrm{i}}\left(\mathrm{w}_{\mathrm{i}} \cdot \mathrm{LPV}_{\mathrm{i}}\right) \\
\mathrm{OPV}=\sum_{\mathrm{i}}\left(\mathrm{w}_{\mathrm{i}} \cdot\left(\mathrm{LPV}_{\mathrm{i}}\right)^{2}\right)
\end{gathered}
$$

where

$$
\sum_{\mathrm{i}} \mathrm{w}_{\mathrm{i}}=1 \text { and } \mathrm{w}_{\mathrm{i}} \geq 0
$$

The WP was first proposed by Derringer (1994). The meaning of weights is less intuitive than in the case of
WS (Choo and Wedley, 2008). The WP has the following characteristic: if LPV of a given criterion is equal to zero (the satisfaction of this criterion is null), then the resulted OPV is equal to zero too (unacceptable concept) whatever the LPVs of the other criteria. The OPV is expressed by

$$
\mathrm{OPV}=\prod_{\mathrm{i}}\left(\left(\mathrm{LPV}_{\mathrm{i}}\right)^{\mathrm{w}_{\mathrm{i}}}\right), \text { where } \sum_{\mathrm{i}} \mathrm{w}_{\mathrm{i}}=1 \text { and } \mathrm{w}_{\mathrm{i}} \geq 0
$$

Kim and Lin (2000) aggregation operator does not allow any kind of compensation between criteria. Its use is very limited in engineering design. The OPV is expressed by

$$
\mathrm{OPV}=\min \left(\mathrm{LPV}_{\mathrm{i}}\right)
$$

TOPSIS is an aggregation operator that was developed by Chen and Hwang (1992) and has been widely applied by other researchers (Cheng et al., 2003; Deng et al., 2000; Montanari, 2004; Singh and Agrawal, 2012; Tong et al., 2004). In the conceptual design phase, TOPSIS has been used in a very limited way (Chang and Chen, 2014; Lin et al., 2008). The basic principle is that the best concept should have the shortest distance from the ideal concept and the farthest distance from the negative-ideal concept. The TOPSIS procedure consists of the following steps: (1) calculate the normalized decision matrix, (2) calculate the weighted normalized decision matrix, (3) determine the ideal and negativeideal concept, (4) calculate the separation measures from the ideal and negative-ideal concept $\left(\mathrm{A}^{-}\right.$and $\mathrm{A}^{+}$, respectively) using the $\mathrm{n}$-dimensional Euclidean distance and (5) calculate the relative closeness to the ideal concept, and (vi) calculate the OPV of each concept by the following formula

$$
\mathrm{OPV}=\frac{\mathrm{A}^{-}}{\mathrm{A}^{-}+\mathrm{A}^{+}}
$$

The separation measures from the ideal and negative-ideal concept for the concept $i$ are calculated by the following formula

$$
\begin{aligned}
& \mathrm{A}_{\mathrm{i}}^{+}=\sqrt{\sum_{\mathrm{j}=1}^{\mathrm{n}}\left(\mathrm{LPV}_{\mathrm{ij}}-\mathrm{LPV}_{\mathrm{j}}^{+}\right)^{2}} \\
& \mathrm{~A}_{\mathrm{i}}^{-}=\sqrt{\sum_{\mathrm{j}=1}^{\mathrm{n}}\left(\mathrm{LPV}_{\mathrm{ij}}-\mathrm{LPV}_{\mathrm{j}}^{-}\right)^{2}}
\end{aligned}
$$

where $\mathrm{LPV}_{\mathrm{j}}^{-}$is the minimum LPV for criterion $\mathrm{j}$ and $\mathrm{LPV}_{\mathrm{j}}^{+}$is the maximum LPV for criterion $\mathrm{j}$.

CP was developed by Zeleny and Cochrane (1973). The basic principle of CP is that the best concept should 
have the shortest distance from the ideal solution. The OPV is expressed by

$$
\mathrm{OPV}=1-\left(\sum_{\mathrm{j}=1}^{\mathrm{n}}\left(\mathrm{w}_{\mathrm{i}} \frac{\left|\mathrm{LPV}_{\mathrm{j}}^{+}-\mathrm{LPV}_{\mathrm{j}}\right|}{\left|\mathrm{LPV}_{\mathrm{j}}^{+}-\mathrm{LPV}_{\mathrm{j}}^{-}\right|}\right)^{\mathrm{p}}\right)^{1 / \mathrm{p}},
$$

where $\sum_{\mathrm{i}} \mathrm{w}_{\mathrm{i}}=1$ and $\mathrm{w}_{\mathrm{i}} \geq 0$

where $\mathrm{LPV}_{\mathrm{j}}^{+}$and $\mathrm{LPV}_{\mathrm{j}}^{-}$have the same meaning as in TOPSIS. The parameter $\mathrm{p}$ defines the desired type of distance. In this study, the CP method has been applied twice with parameter $\mathrm{p}$ equals to 1 and 2 .

The ELECTRE I belongs to the family of outranking methods. It is widely used by DMs in many fields. It was first developed by Roy (1968). ELECTRE I procedure consists of the following steps: (1) define a concordance index for each pair of concepts, which represents the sum of weights of attributes for which concept $\mathrm{A}$ is better than $\mathrm{B}$; (2) define a discordance index for each pair of concepts, which denotes the absolute difference of this pair of attributes divided by the maximum difference over all pairs; (3) establish threshold values for the two indices; and (4) generate the set of concepts that is not outranked by any other concept. In this study, the thresholds used for concordance and discordance indexes are, respectively, 0.7 and 0.2 .

\section{Evaluation of MCDA methods: relevant criteria to consider}

In this section, the objective is to identify the relevant criteria to take into account when evaluating and selecting a MCDA method for the context of decisionmaking in conceptual design. In section 'State of the art', the review of the state of the art highlights the difficulties of selecting a MCDA method and indicates that the choice of the relevant criteria to take into account is very dependent on the decision-making context. Therefore, the argumentation provided in proposed reasoning is specific to the context of decisionmaking in the conceptual design.

\section{Adaptation of the type of results the method is expected to bring}

Most authors dealing with the issue of MCDA method selection admit that this criterion must be considered (Guitouni and Martel, 1998; Mahmoud and Garcia, 2000; Ozernoy, 1988; Roy and Slowinski, 2013; Zanakis et al., 1998). Roy and Slowinski (2013) claim that this criterion is the first and the most important to take into account. For example, if the DM want to get a complete ordering of initial concepts, then the family of outranking methods is not appropriate. In the conceptual design phase, due to the limited number of design concepts and the critical importance of concept choice, results produced by the MCDA method must provide as much information as possible about design concepts in order to ease decision-making and reduce the risk. Thereby, a utility value with cardinal meaning can be required by DMs because it allows not only to determine a ranking but also to measure how much each concept is better than another one. This is important information to have since rank reversal could take place due to uncertainties in input information. It is also useful in helping the allocation of resources among many design concepts when the DM aims to develop many concepts in parallel to finally select the most suitable one. We assume that the adaptation of the type of results the method is expected to bring with the decision-making situation is a crucial criterion. In the industrial case being studied, the MCDA method is expected to produce a utility value with cardinal meaning.

\section{Correct handling of input information}

Input information refers to the relative importance of the different criteria and preferences related to the satisfaction of these criteria by initial concepts. This information can take various forms (Choo et al., 1999; Roy and Slowinski, 2013; Vincke, 1982): ordering of criteria, ordering of some concepts, acceptable tradeoffs, pairwise comparisons of some concepts, assignment of some concepts to categories, assessment of lotteries, presence of veto and so on. Each MCDA method requires a certain form of input information. Many authors claim that the input information required by a MCDA method must be the same as the available input information (Guitouni and Martel, 1998; Ozernoy, 1988; Roy and Slowinski, 2013; Stewart, 1992). This condition can be very restrictive in some cases because many forms of input information exist. In addition, other conditions could be required by a MCDA method. Roy and Slowinski (2013) recommend modifying input information if necessary to adapt it for a given MCDA method. They also recommend taking some precautions for such a transformation, especially to avoid degrading the quality of the information. In the studied case, the types of input information available are utility values with cardinal meaning (see section 'Input information'), for both design concepts and criteria. This can be transformed into another kind of information. For example, in order to be adapted to PROMETHEE (Preference Ranking Organisation METHod for Enrichment Evaluation) method, it can be converted into preference relations. However, such a transformation leads to a loss of some information on 
initial concepts. In the case of conceptual design, the number of design concepts is limited (three in the industrial case being studied) and the concept choice has a crucial importance for the success of the development project. Such a loss of information is difficult for the DM to accept. We argue that the 'correct handling of input information' criterion is another essential criterion to respect in the present context. For the industrial case being studied, input information is given in section 'Input information'.

\section{Adaptation of the degree of compensation}

Broadly speaking, compensation refers to the existence of 'tradeoffs', that is, the possibility of offsetting a 'disadvantage' on some criterion by a sufficiently large 'advantage' on another criterion - whereas smaller 'advantages' would not do the same (Bouyssou, 1986). Each MCDA method has its own compensation strategy. When using an aggregation operator in engineering design, one of the characteristics required by this compensation strategy is the respect the axiom of annihilation (Biegel and Pecht, 1991; Otto and Antonsson, 1993; Scott, 1999; Vincent, 1983). This condition restricts considerably the field of aggregation operators usable for engineering design. However, it is not a guarantee that the degree of compensation of the chosen aggregation operator is consistent with DM attitude since there is a multitude of possible degrees of compensation. The main issue is that there is no recognized approach, to our knowledge, to characterize the degree of compensation of a MCDA method. In the present case, since the results produced by a MCDA method must be as consistent as possible with DM preference (given the importance of concept choice), we claim that it is important to consider this criterion. In section 'Results and interpretation', it can be seen that two aggregation operators (WP and KL) yield significantly different OPVs even if they respect the two criteria cited before ('Adaptation of the type of results the method is expected to bring' and 'Correct handling of input information') and axioms of Scott (that includes the axiom of annihilation). The reason is that the degrees of compensation of these two aggregation operators are significantly different.

\section{Case study}

The product considered in this article is a Fresnel solar collector. Its function in a concentrated solar power (CSP) plant is to concentrate and redirect sunlight onto absorber tubes to heat up the working fluid. The cost of raw material for the manufacturing of solar collectors represents $50 \%$ of investment cost for a CSP plant (Kumara et al., 2015). Three concepts have been proposed initially: truss structure (S1), sandwich structure (S2) and tube structure (S3). The criteria taken into account in this study are as follows: elastic deflection $(\mathrm{C} 1)$, angular elastic deformation $(\mathrm{C} 2)$, raw material cost (C3), durability (C4), development time (C5) and acquisition cost of manufacturing machinery (C6). The criteria $\mathrm{C} 1$ and $\mathrm{C} 2$ are related to optical performance.

\section{Input information}

As described in section 'Introduction', a set of input information needs to be prepared before using a MCDA method. This input information is decomposed into: information expressing relative importance of the different criteria and information related to the satisfaction of the different criteria by initial concepts. It is important to note that the same input information is used for all MCDA methods compared in this article.

It is difficult and risky to directly assign weights to criteria from heterogeneous natures. Analytic hierarchy process (AHP) was used in this study since it uses pairwise comparison which is well adapted as preference elucidation mode to deal with heterogeneous criteria (Guitouni and Martel, 1998; Vincke, 1982). Using a semantic scale, pairwise comparisons between criteria were performed by DM and the outcomes form a judgement matrix. The matrix normalization method proposed by LeBel (2009) was then used to obtain criteria weights from the judgement matrix. In order to limit the inconsistencies that occur when performing pairwise comparisons, the consistency ratio (CR) proposed by Saaty (1977) was used as a guidance to check the degree of consistency. As recommended by Saaty, a value of 0.1 was used as threshold for CR (Saaty, 1977). Criteria weights obtained using AHP are shown in Table 2.

In this industrial context, the design activity is very collaborative since many stakeholders are involved in the product development process. As a consequence, there is a need to normalize the preference related to the achievement of the different criteria for easier collaboration between stakeholders. In this study, we chose to use LPV, which is a utility value (with cardinal meaning) that measures the degree of achievement of a criterion by a given concept. In this article, this is between 0 and 1 . This normalization of preference can be easily understood by the different stakeholders in the development project. As explained in section 'Introduction', a set of observation data (mass, maximum stress, carbon footprint, etc.) is needed before establishing LPVs. Contrary to these observation data, the determination of LPVs is dependent on DMs preferences. Therefore, they must be established in close cooperation with DMs. 
Table 2. Criteria weights and fuzzy LPVs for the three concepts.

\begin{tabular}{lllllll}
\hline & CI & C2 & C3 & C4 & C5 & C6 \\
\hline $\begin{array}{lllll}\text { Criteria } \\
\text { weights }\end{array}$ & 0.017 & 0.1 & 0.494 & 0.067 & 0.048 & 0.274 \\
SI: truss & $(0.88,0.99,0.99)$ & $(0.32,0.35,0.57)$ & $(0.75,0.90,0.91)$ & $(0.35,0.50,0.61)$ & $(0.17,0.20,0.37)$ & $(0.25,0.27,0.57)$ \\
S2: sandwich & $(0.49,0.50,0.51)$ & $(0.64,0.65,0.67)$ & $(0.50,0.52,0.52)$ & $(0.61,0.62,0.66)$ & $(0.64,0.65,0.66)$ & $(0.65,0.67,0.70)$ \\
S3: tube & $(0.49,0.50,0.52)$ & $(0.85,0.90,0.91)$ & $(0.52,0.57,0.58)$ & $(0.69,0.80,0.90)$ & $(0.46,0.48,0.52)$ & $(0.40,0.42,0.60)$
\end{tabular}

LPV: local preference value.

Compared to aleatory uncertainties, epistemic uncertainties are predominant in the early phases of the development process (Antonsson and Otto, 1995). Triangular fuzzy numbers were used to represent imprecision in LPVs in the present case since they are more suitable to deal with epistemic uncertainties. In this case, three values are assessed to represent imprecision in LPV of a given concept against a given criterion: the lowest possible value $\mathrm{LPV}_{\mathrm{l}}$, the most likely value $\mathrm{LPV}_{\mathrm{m}}$, and the highest possible value $\mathrm{LPV}_{\mathrm{h}}$. The results are shown in Table 2 (they are expressed in the form $\left(\mathrm{LPV}_{l}\right.$, $\mathrm{LPV}_{\mathrm{m}}, \mathrm{LPV}_{\mathrm{h}}$ ). The main sources of imprecision in LPVs are as follows:

- Errors when fixing embodiment design choices (selections of structural dimensions, materials, components, etc.): It is considered as the most important imprecision source in the early design phases. As investigations about concepts progress, these errors are progressively reduced.

- The low exactness of behaviours models used to evaluate observational data: Given the hypothesis adopted in these models, their capacity to represent product behaviours is limited.

In order to simplify the process of assessing LPVs, preference functions are initially established by DM for each criterion and allow the mapping between observation variables (mass, maximum stress, etc.) and LPVs. They make it possible to capture and capitalize decision-making aims towards observation variables.

\section{Results and interpretation}

In the first part of this section, the three initial concepts are ranked with the MCDA methods presented in section 'Presentation of MCDA methods'. Results are then analysed considering the criteria cited in section 'Evaluation of MCDA methods: relevant criteria to consider'. In the first part of this section, only nominal values of LPVs are considered $\left(\mathrm{LPV}_{\mathrm{m}}\right)$ and no sensitivity analysis is performed. In the second part of this section, sensitivity analyses are performed and results are

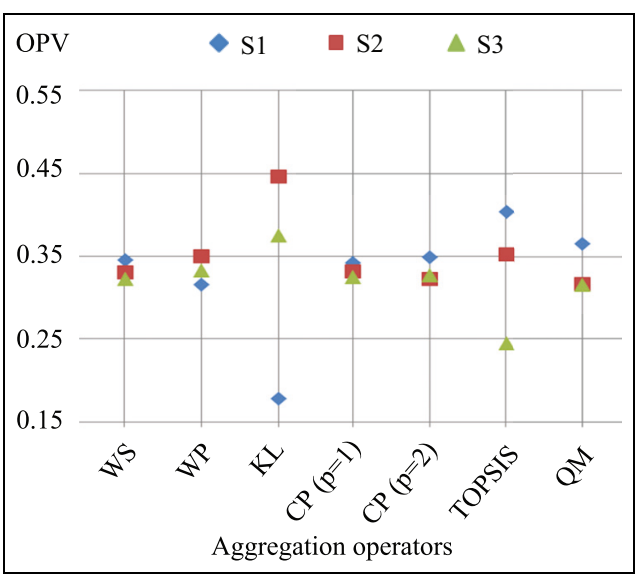

Figure I. Ranking of initial concepts by aggregation operators.

then interpreted. The objective in this second part is to highlight the limitations of the standard application of a MCDA method and demonstrate that sensitivity analysis can improve the benefit of using a MCDA method in the presence of imprecise information due to the immaturity of initial concepts.

Figure 1 shows OPVs obtained using the seven aggregation operators. The concepts outranked by ELECTRE I are S2 and S1. As shown in Figure 1, clear discrepancies are observed in concepts ranking between the different aggregation operators. This confirms the need to adopt a methodology to select a MCDA method to avoid misleading DM. Apart from TOPSIS and KL aggregation operators, it can be seen, for the other aggregation operators, that OPVs produced for the different concepts are substantially similar to each other. It is thus difficult and risky for DMs to draw a conclusion based on these results since a small error in LPVs could provoke a rank reversal.

The seven aggregation operators respect the criteria 'Adaptation of the type of results the method is expected to bring' and 'Correct handling of input information' since they all use utility values with cardinal meaning, as input information (called LPVs in this study) and produce a utility value, also with cardinal meaning, as an output result (called OPV in this study), 
which is desirable in decision-making situation being considered.

TOPSIS, which is widely used in the literature (Chang and Chen, 2014; Cheng et al., 2003; Deng et al., 2000; Montanari, 2004; Singh and Agrawal, 2012; Tong et al., 2004), has a high degree of compensation since it greatly intensifies the effect of high LPVs. This intensification effect is mainly attributed to the use of a sum of an Euclidean distance to calculate the closeness of initial concepts to the reference concepts. In addition, this aggregation operator does not satisfy the axiom of annihilation that is fundamental in engineering design (Biegel and Pecht, 1991; Otto and Antonsson, 1993; Scott, 1999; Vincent, 1983). Another inconvenient is that this aggregation operator is not the same for all decision-making problems since it uses distances from reference concepts, which depend on the set of concepts being studied. This is manifested by the non-respect of the axiom of idempotency (Table 1).

TOPSIS and CP ( $p=1$ and $p=2)$ have, as a common feature, the use of a distance from a reference concept. In addition, the family of $\mathrm{CP}$ operators has the advantage of allowing different degrees of compensation (by varying $\mathrm{p})$. However, as TOPSIS, CP $(\mathrm{p}=1)$ and $\mathrm{CP}(\mathrm{p}=2)$ do not satisfy the axioms of annihilation and idempotency. Therefore, they cannot be used in the present case.

Compared to WS, QM has a higher degree of compensation since it uses the sum of the square of the terms LPVs, which intensify the impact of highly satisfied criteria (high LPV). However, these two aggregation operators do not satisfy the axiom of annihilation. Their use is thus not appropriate in the present case. ELECTRE I produces only an outranking relation between initial concepts. Compared to utility values (with cardinal meaning), this type of result bring little information on initial concepts. The criterion 'Adaptation of the type of results the method is expected to bring' is thus not respected for the case of ELECTRE I. Its use is thus not appropriate in the present case.

According to this analysis, it appears that only WP and KL aggregation operator respect the seven axioms of Scott (1999) and the two criteria 'Adaptation of the type of results the method is expected to bring' and 'Correct handling of input information'. Concerning the criterion 'Adaptation of the degree of compensation', it is clear that WP has a higher degree of compensation than KL. In fact, KL does not provide any kind of compensation between criteria. Its use is thus reserved for the case DM is extremely conservative (any compensation between criteria is allowed) is its decision-making attitude. In the industrial case being studied, DM aims to have a kind of compensation between criteria. Therefore, we conclude that WP is the most appropriate among the initial MCDA methods.

If we go back to Table 2, it can be seen that the truss concept, which is considered as a new and immature concept for the company, is of a real interest for some criteria compared to the other concepts, especially for the criterion 'raw material cost' which is the most important criterion in this industrial case. In contrast, it reveals very low LPVs for other criteria $(\mathrm{C} 2, \mathrm{C} 5, \mathrm{C} 6)$. Especially for the criterion 'acquisition cost of manufacturing machinery' which also has a strong importance in this industrial case. Since conservative aggregation operators (respecting the axiom of annihilation) intensify the impact of criteria whose LPVs are close to zero (Scott, 1999), the truss concept obtains a low OPV with WP and KL aggregation operators (they both respect the axiom of annihilation). In practice, when the evaluation of an immature concept reveals that it does not satisfy some criteria (or very weakly), designers do not systematically reject the concept. They consider that modifications could eventually be introduced in embodiment design choices (selections of

Table 3. Summarization of comparison results (of MCDA methods).

\begin{tabular}{|c|c|c|c|}
\hline & $\begin{array}{l}\text { Correct handling } \\
\text { of input } \\
\text { information }\end{array}$ & $\begin{array}{l}\text { Adaptation of the type } \\
\text { of results the method } \\
\text { is expected to bring }\end{array}$ & Respect of axioms of Scott \\
\hline WS & Appropriate & Appropriate & No (axiom of annihilation) \\
\hline WP & Appropriate & Appropriate & Yes \\
\hline Kim and Lin & Appropriate & Appropriate & Yes \\
\hline$C P(p=1)$ & Appropriate & Appropriate & No (axioms of annihilation and idempotency) \\
\hline$C P(p=2)$ & Appropriate & Appropriate & No (axioms of annihilation and idempotency) \\
\hline TOPSIS & Appropriate & Appropriate & No (axioms of annihilation and idempotency) \\
\hline ELECTRE I & Not appropriate & Not appropriate & Not concerned \\
\hline Quadratic mean & Appropriate & Appropriate & No (axiom of annihilation) \\
\hline
\end{tabular}

MCDA: multi-criteria decision aiding; WS: weighted sum; WP: weighted product; CP: compromise programming; TOPSIS: Technique for Order Preference by Similarity to Ideal Solution; ELECTRE: ELimination Et Choix Traduisant la REalité. 
structural dimensions, materials, components, etc.) during the development process in order to insure better LPVs of these weakly satisfied criteria. In the present case, for example, the high potential of improvement in the truss structure makes it particularly attractive for DMs. Using a deterministic value is thus not adapted when dealing with immature concepts and imprecision and this is particularly true when using conservative aggregation operator.

According to this first analysis (summarized in Table 3), WP is the most appropriate MCDA method in our case (compared to the other MCDA methods compared) since it respects the seven axioms of Scott (1999) and the two criteria 'Adaptation of the type of results the method is expected to bring' and 'Correct handling of input information'. However, the following limits can be remarked in yielded results: (1) it is very difficult and risky to draw a conclusion when OPV is similar to each other, and (2) the use of a conservative aggregation operator (respecting the axiom of annihilation) systematically discriminates immature concepts. In the rest of this section, sensitivity analyses are performed in an attempt to address these problems. In the rest of the proposed analysis, it is assumed that WP is chosen since it corresponds to the most appropriate aggregation operators (compared to the initial MCDA methods compared).

The impact of certain LPVs on OPV can be more or less high depending on the degree of compensation of the MCDA method and the criterion weight. For example, an aggregation operator with low degree of compensation accentuates the impact of criteria with low LPVs. In this study, a first sensitivity study called 'local sensitivity study' is performed. For a given concept, a sensitivity calculation using Monte Carlo simulation is performed for each criterion, that is, the imprecision in LPV for the criterion concerned (shown in Table 2) is propagated through WP towards OPV. The three estimates $\mathrm{LPV}_{\mathrm{l}}, \mathrm{LPV}_{\mathrm{m}}$ and $\mathrm{LPV}_{\mathrm{h}}$ (Table 2) define a triangular probability distribution, which is used by Monte Carlo simulation. All statistical properties of this distribution are uniquely determined by the three estimates. For the other criteria, LPV is assumed to be fixed (equal to $\mathrm{LPV}_{\mathrm{m}}$ ). The results of local sensitivity study are shown in Table 4 and are expressed in terms of standard deviations of OPVs. The interest of local sensitivity study is to identify inputs (LPVs) that cause significant uncertainty (high standard deviation) in the output (OPV) and that should therefore be the focus of attention, even by a reassessment or by further investigations. Since WP has been chosen as the most appropriate MCDA method in the present case, the standard deviation resulting from the other MCDA methods can be ignored. In Table 4, the standard deviations with bold characters are those which need to be reassessed in

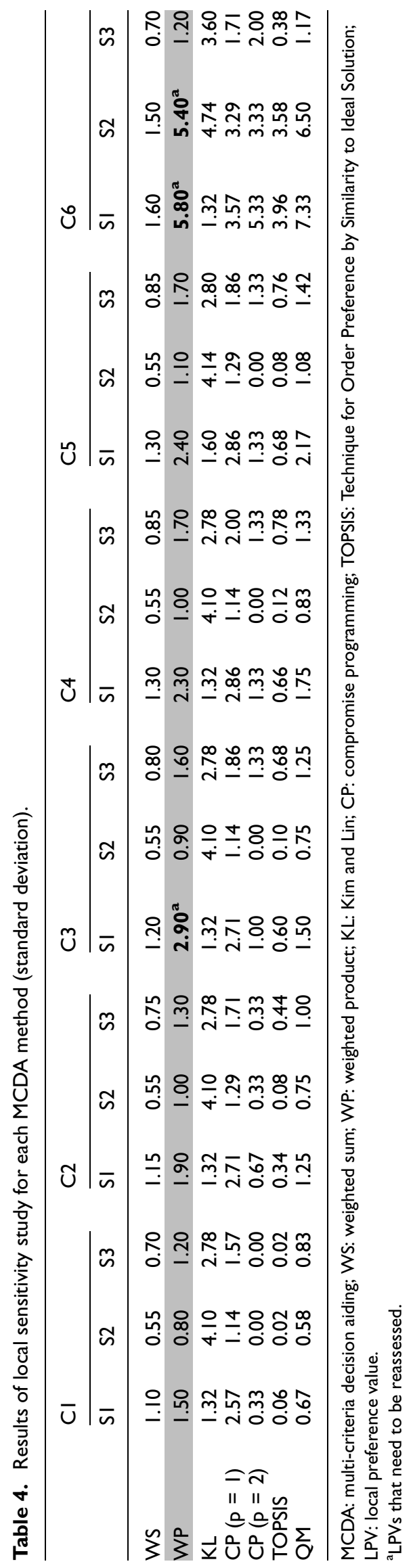




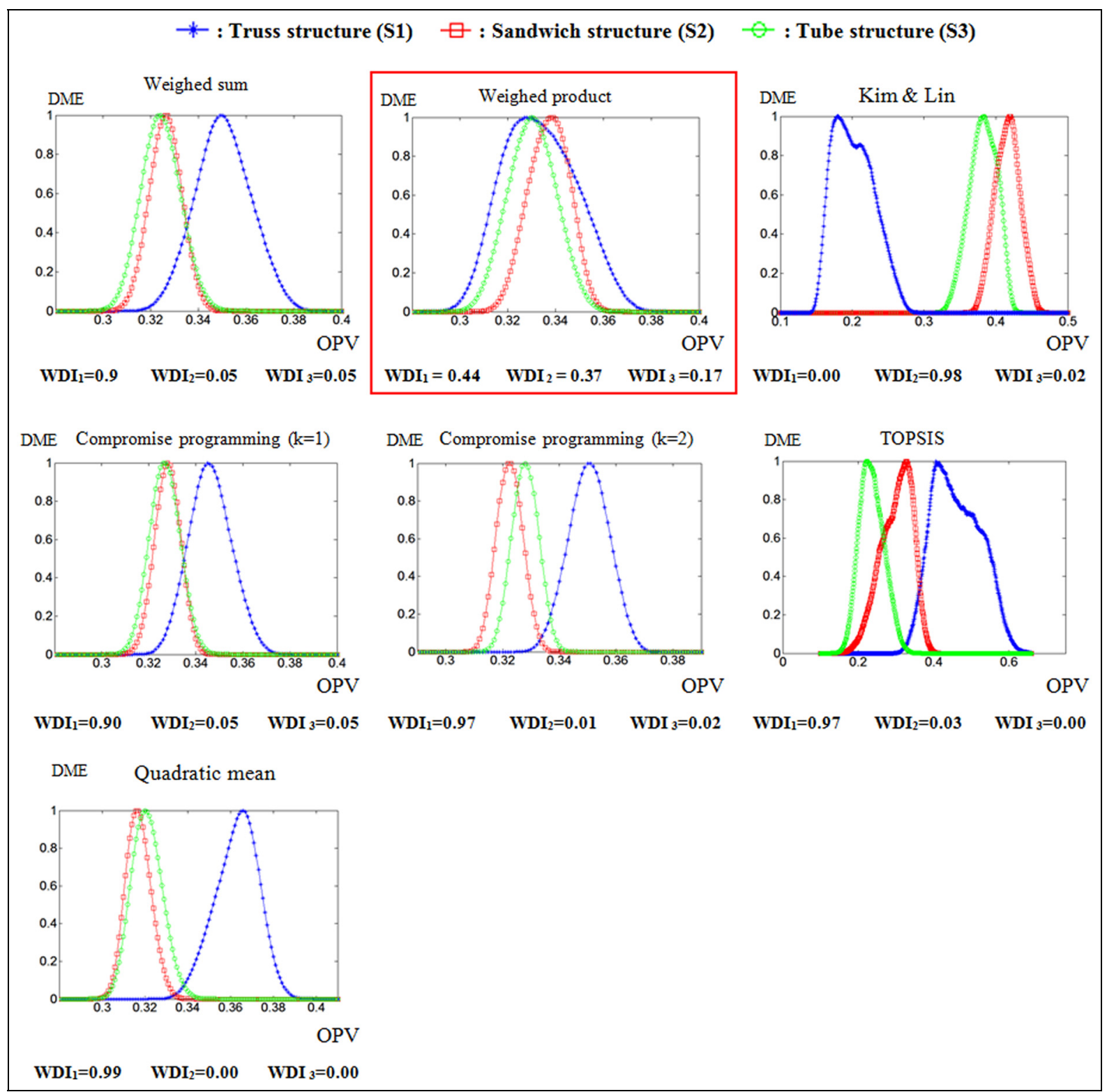

Figure 2. Results of global sensitivity analysis for each MCDA method.

DME: degree of membership.

the present case. The local sensitivity analysis has no impact on the choice of MCDA method. Its unique interest is to improve the quality of LPVs assessments.

A 'global sensitivity study' is then performed. For a given concept, a unique sensitivity calculation using Monte Carlo simulation is performed to propagate, simultaneously, the imprecision of all LPVs (corresponding to all criteria) through WP towards OPV. Such a study makes it possible to explore the potential of improving OPV. The results are shown in Figure 2. It represents the degree of membership (DME) as a function of OPV. The analysis is performed for each concept. Starting from this analysis, the function of weak dominance index (WDI) introduced by Roubens (1989) is used to exploit fuzzy ranking results. It can be interpreted as the truth value of the statement 'concept $\mathrm{A}$ is better than each of other concept'. When using Monte Carlo analysis, it can be calculated by equation (9). NS is the number of samples where OPV of concept $\mathrm{A}$ is greater than the others. $\mathrm{N}$ is the total number of samples.

$$
\mathrm{WDI}=\frac{\mathrm{NS}}{\mathrm{N}}
$$




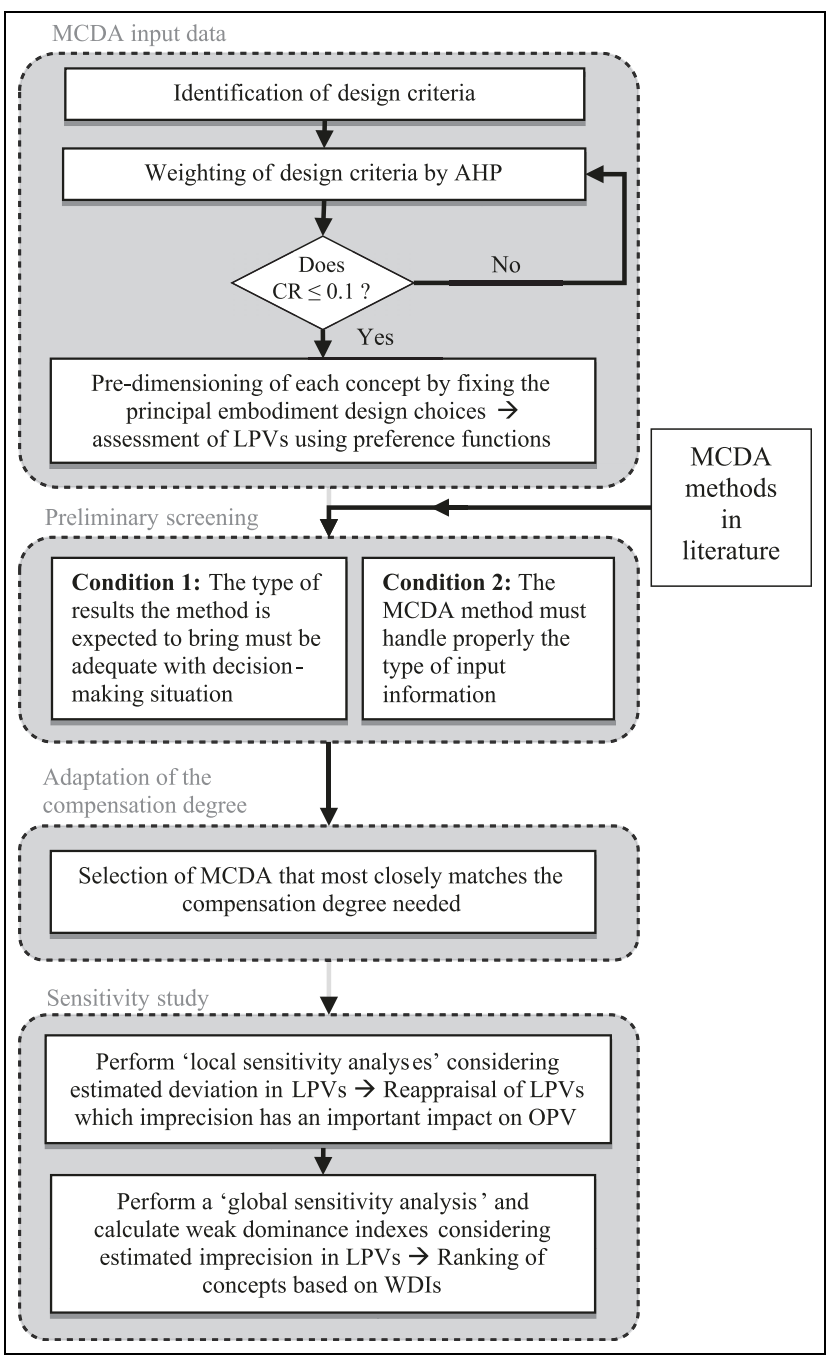

Figure 3. General framework used to choose and use a MCDA method in the present industrial case.

Figure 2 shows the results of the WDIs calculation. Considering WP outcomes, it can be seen that the new ranking obtained by WDIs differs considerably from that obtained in Figure 1. Using WDIs allows taking into account imprecision in embodiment design choices (dimensions, materials, etc.) and thus considers the possibilities of improvement of the product. We therefore argue that the ranking obtained using WDI is more consistent than the first ranking (Figure 1) and that it is more appropriate for highlighting the potential of immature concepts. However, we argue that it is important to build judgements not only on WDI values but also graphically by analysing the curves of DME as a function of OPV.

Figure 3 gives a summary of the different steps followed in this article to choose and apply a MCDA method in the present industrial case. As shown in this figure, the input data are first generated (LPVs and criteria weights). Then, the most appropriate MCDA method is chosen by considering the three criteria in section 'Evaluation of MCDA methods: relevant criteria to consider'. Finally, sensitivity analysis are performed to improve the quality of LPVs (global sensitivity analysis) and then to improve the consistency of final ranking (global sensitivity analysis).

\section{Conclusion and future work}

Decision-making in conceptual design phase has a very important impact on the global life-cycle cost. Therefore, it must be structured by the appropriate theories and methodologies. A comparative study of MCDA methods of different kinds was performed in this study. We argue that the most relevant criteria to consider in the context of decision-making in conceptual design are as follows: adaptation of the type of results the method is expected to bring, correct handling of input information and adaptation of the degree of compensation. In addition, when using an aggregation operator, it must verify the axioms of Scott (1999) to be design-appropriate. Considering these criteria, it was found that WP is the most suitable MCDA methods in the present industrial case (compared to the other MCDA methods studied).

It was found that the application of sensitivity study (global sensitivity study) can improve the benefit of using the chosen MCDA method in the presence of imprecise information since it allows DM to explore more effectively the potential of improvement of immature concepts. The new ranking obtained using the degree of weak dominance is more consistent with DM preferences. Another sensitivity study (local sensitivity study) was applied individually on the different LPVs in order to improve their quality by a reappraisal of LPVs which imprecision has an important impact on OPV.

However, two main issues are still open: (1) the true meaning and the validity of criteria weights are crucial in order to avoid improper use of the MCDA methods, and (2) there is no recognized approach, to our knowledge, to characterize the degree of compensation of a MCDA method. In the present case, since the results produced by MCDA method must be as consistent as possible with DM preference (due to the importance of decisions in conceptual design); we consider that these issues are important and must be investigated for future research.

\section{Declaration of conflicting interests}

The author(s) declared no potential conflicts of interest with respect to the research, authorship and/or publication of this article. 


\section{Funding}

The author(s) received no financial support for the research, authorship and/or publication of this article.

\section{References}

Antonsson EK and Otto KN (1995) Imprecision in engineering design. Journal of Mechanical Design, Transactions of the ASME 117(B): 25-32.

Belton V and Stewart TJ (2002) Multiple Criteria Decision Analysis: An Integrated Approach. Boston, MA: Kluwer Academic.

Biegel P and Pecht M (1991) Design trade-offs made easy. Concurrent Engineering: Research and Applications 1(3): 29-40.

Bouyssou D (1986) Some remarks on the notion of compensation in MCDM. European Journal of Operational Research 26(1): 150-160.

Chang H-C and Chen H-Y (2014) Optimizing product form attractiveness using Taguchi method and TOPSIS algorithm: a case study involving a passenger car. Concurrent Engineering: Research and Applications 22(2): 135-147.

Chen SJ and Hwang CL (1992) Fuzzy Multiple Attribute Decision Making: Methods and Applications. Berlin: SpringerVerlag.

Cheng S, Chan CW and Huang GH (2003) An integrated multi-criteria decision analysis and inexact mixed integer linear programming approach for solid waste management. Engineering Applications of Artificial Intelligence 16: 543-554.

Choo EU and Wedley WC (2008) Comparing fundamentals of additive and multiplicative aggregation in ratio scale multi-criteria decision making. The Open Operational Research Journal 2: 1-7.

Choo EU, Schoner B and Wedley WC (1999) Interpretation of criteria weights in multicriteria decision making. Computers \& Industrial Engineering 37: 527-541.

Deng H, Yeh CH and Willis RJ (2000) Inter-company comparison using modified TOPSIS with objective weights. Computers \& Operations Research 27(10): 963-973.

Derringer R (1994) A balancing act: optimizing a product's properties. Quality Progress 27(6): 51-58.

Fodor JC and Roubens M (1994) Fuzzy Preference Modeling and Multi-Criteria Decision Aid. Dordrecht: Kluwer Academic.

Grabisch M (1996) The application of fuzzy integrals in multicriteria decision making. European Journal of Operational Research 89: 445-456.

Guitouni A and Martel JM (1998) Tentative guidelines to help choosing an appropriate MCDA method. European Journal of Operational Research 109: 501-521.

Hobbs BF, Chankong V, Hamadeh W, et al. (1992) Does choice of multicriteria method matter? An experiment in water resources planning. Water Resources Research 28(7): $1767-1779$.

Keeney RL and Raiffa H (1994) Decisions with Multiple Objectives: Preferences and Value Tradeoffs. Cambridge: Cambridge University Press.
Kim K and Lin D (2000) Simultaneous optimization of mechanical properties of steel by maximizing exponential desirability functions. Journal of the Royal Statistical Society Series C: Applied Statistics 49(3): 311-325.

Kumara V, Shrivastavaa RL and Untawaleb S-P (2015) Fresnel lens: a promising alternative of reflectors in concentrated solar power. Renewable and Sustainable Energy Reviews 4: 376-390.

LeBel L (2009) Prise de décision multi critères, Prise de décision Multi critères. Québec City, QC, Canada: Université Laval.

Lin MC, Wang CC, Chen MS, et al. (2008) Using AHP and TOPSIS approaches in customer-driven product design process. Computers in Industry 59: 17-31.

Mahmoud MR and Garcia LA (2000) Comparison of different multicriteria evaluation methods for the Red Bluff diversion dam. Environmental Modelling \& Software 15: 471-478.

Masseia G, Rocchia L, Paolottia L, et al. (2014) Decision support systems for environmental management: a case study on wastewater from agriculture. Journal of Environmental Management 146: 491-504.

Montanari R (2004) Environmental efficiency analysis for Fresnel thermo-power plants. Journal of Cleaner Production 12: 403-414.

Otto KN and Antonsson EK (1993) The method of imprecision compared to utility theory for design selection problems. Design Theory and Methodology - DTM';93 53: $167-$ 173.

Ozernoy VM (1988) Some issues in designing an expert system for multiple criteria decision making. Acta Psychologica 68: 237-253.

Roubens M (1989) Some properties of choice functions based on valued binary relations. European Journal of Operational Research 40: 309-321.

Roy B (1968) Classement et choix en présence de points de vue multiples, Revue française d'automatique. d'informatique et de recherche opérationnelle 2: 57-75.

Roy B and Slowinski R (2013) Questions guiding the choice of a multicriteria decision aiding method. EURO Journal on Decision Processes 1: 69-97.

Saaty TL (1977) A scaling method for priorities in hierarchical structures. Journal of Mathematical Psychology 15: 234-281.

Scott MJ (1999) Formalizing negotiation in engineering design. $\mathrm{PhD}$ Thesis, California Institute of Technology, Pasadena, CA.

Simon HA (1960) The New Science of Management Decision. New York: Harper \& Row.

Singh T and Agrawal VP (2012) Concurrent design of a nanoactuator for 'X-abilities' using the multiple-attribute decision-making approach. Concurrent Engineering: Research and Applications 20(4): 301-314.

Stewart TJ (1992) A critical survey on the status of multiple criteria decision making theory and practice. Omega 20(5-6): 569-586.

Sun X, Meng P, Boehnke D, et al. (2012) Multi-criteria decision analysis techniques in aircraft conceptual design process. In: 28th congress of the international council of the 
aeronautical sciences 2012 (ICAS 2012), vol. 5, pp. 3975-3984.

Tong LI, Wang CH, Chen CC, et al. (2004) Dynamic multiple responses by ideal solution analysis. European Journal of Operational Research 156: 433-444.

Triantaphyllou E and Lin CT (1996) Development and evaluation of five fuzzy multiattribute decision-making methods. International Journal of Approximate Reasoning 14(4): 281-310

Vincent T (1983) Game theory as a design tool. ASME Journal of Mechanisms, Transmissions, and Automation in Design 105: 165-170.
Vincke PH (1982) Preference modelling: a survey and an experiment. In: Brans JP (ed.) Operational Research'81. Amsterdam: North-Holland, pp. 341-353.

Zanakis SH, Solomon A, Wishart N, et al. (1998) Multi-attribute decision making: a simulation comparison of select methods. European Journal of Operational Research 107: 507-529.

Zeleny M and Cochrane JL (1973) Compromise Programming: Multicriteria Decision Making. Columbia, SC: University of South Carolina Press, pp. 262-301.

Zimmer L and Zablit P (2001) Global aircraft predesign based on constraint propagation and interval analysis. In: Proceedings of CEAS conference on multidisciplinary aircraft design and optimisation, Köln.

\section{Author biographies}
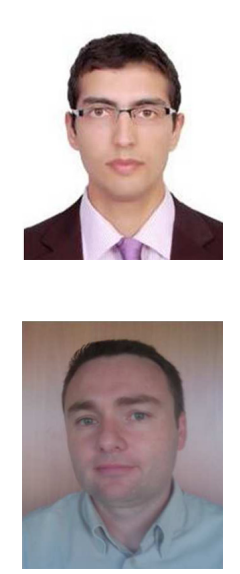

Mehdi El Amine is a PhD student in Arts \& Métiers ParisTech engineering school (Bordeaux), and also a member of the Mechanical and Engineering Institute of Bordeaux (I2M). His main research topics include decision-making in design engineering, design methodologies, physical modelling, 3D-CAD system, CAE.

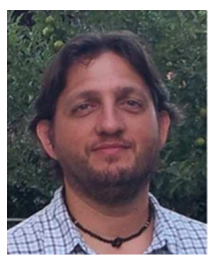

Jérôme Pailhès received his $\mathrm{PhD}$ degree from the University of Bordeaux, France in 1999 . He is currently an Assistant Professor in the Arts et Métiers ParisTech engineering school (Bordeaux), and also a member of the Mechanical and Engineering Institute of Bordeaux (I2M) from 2001. His main research topics include design engineering methodology, optimization, functional analysis, physical modelling, model-building processes.

Nicolas Perry received his $\mathrm{PhD}$ in material and process interaction from Ecole Centrale de Nantes and Nantes University in 2000. He spent 7 years at IRCCyN (UMR 6597) working as an Assistant Professor in the field of virtual engineering and developing Computer-Aided Systems to help decision-making. He moved to Bordeaux University in 2007 and focused his research activities on the field of composite, integrating manufacturing aspects in the behaviour and design of composite parts in I2M Institute (UMR 5295). He also developed environmental integration into product design (focusing design for recycling and LCA into early product design) and on manufacturing processes (such as additive layer manufacturing). In 2011, he took up the position of professor position at Arts et Métiers ParisTech Bordeaux and co-head of the Mechanical Engineering research team at I2M. 